УДК 81 ' 42

DOI 10.18413/2712-7451-2020-39-3-487-496

\title{
Манипулятивные стратегии и тактики в шванках российских немцев
}

\author{
Чистюхина Е.А., Жукова Л.В. \\ Новосибирский военный институт \\ имени генерала армии И.К. Яковлева войск национальной гвардии Российской Федерации, \\ Россия, 630114, г. Новосибирск, ул. Ключ-Камышенское плато, 6/2 \\ E-mail: etschistjuchina@mail.ru; liebe82@mail.ru
}

\begin{abstract}
Аннотация. В современном языкознании внимание ученых все больше привлекают проблемы живой коммуникации, результатом чего стало появление исследований, посвященных изучению речевого взаимодействия с точки зрения коммуникативных стратегий и тактик на материале текстов разных жанров. Однако многие стратегии и тактики до сих пор не описаны, что обусловлено, с одной стороны, появлением новых типов дискурса, и с другой стороны, многообразием самих речевых стратегий и тактик в уже существующих типах текста. В связи с этим в качестве цели исследования авторы выдвигают выявление и описание речевых тактик и тактических приемов, способствующих актуализации стратегии манипуляции, используемой героями шванков в конкретных ситуациях общения. Стратегия манипуляции воплощается в шванках с помощью различных речевых тактик, которые реализуются многочисленными лексическими, грамматическими и стилистическими средствами. Обладая высокой степенью результативности, манипулятивные стратегии и тактики способствуют достижению главной коммуникативной цели - обличению таких человеческих пороков. В процессе исследования получено представление об особенностях речевого взаимодействия российских немцев, носителей уникальных островных говоров, зафиксированных в текстах шванков. Результаты исследования открывают дальнейшие перспективы для изучения шванков российских немцев в русле коммуникативной прагматики.
\end{abstract}

Ключевые слова: коммуникативное воздействие, речевые стратегии и тактики, манипуляция, шванк, язык российских немцев.

Для цитирования: Чистюхина Е.А., Жукова Л.В. 2020. Манипулятивные стратегии и тактики в шванках российских немцев. Вопросы журналистики, педагогики, языкознания, 39 (3): 487-496. DOI 10.18413/2712-7451-2020-39-3-487-496

\section{Manipulative strategies and tactics in the shvanks of russian germans}

\author{
Eugenia A. Chistjuhina, Lyubov V. Zhukova \\ Novosibirsk military Institute named after general of the Army I.K. Yakovlev \\ of National Guard Troops of the Russian Federation, \\ 6/2 Kljuch-Kamyshenskoeplato St, Novosibirsk, 630114, Russia \\ E-mail: etschistjuchina@mail.ru; liebe82@mail.ru
}

\begin{abstract}
In modern linguistics, the attention of scientists is increasingly drawn to the problems of live communication, which has resulted in the emergence of research devoted to the study of speech interaction in terms of communication strategies and tactics based on texts of different genres. However, many strategies and tactics have not yet been described, which is due, on the one hand, to the emergence of new types of discourse, and on the other hand, to the variety of speech strategies and tactics themselves in existing types of text. In this regard, the authors put forward the identification and description of
\end{abstract}


speech tactics and tactics that contribute to the actualization of the manipulation strategy used by the heroes of schwank in specific situations of communication as the goal of the study. The manipulation strategy is implemented in schwanks using various speech tactics, which are implemented by numerous lexical, grammatical and stylistic means. With a high degree of effectiveness, manipulative strategies and tactics help to achieve the main communicative goal - to expose such human vices. In the course of the research, an idea was obtained about the features of speech interaction of Russian Germans, carriers of unique island dialects recorded in the texts of the schwanks. The results of the research open up further prospects for studying the schwanks of Russian Germans in the context of communicative pragmatics.

Keywords: communicative influence, speech strategies and tactics, manipulation, shvank, language of Russian Germans.

For citation: Chistjuhina E.A., Zhukova L.V. 2020. Manipulative strategies and tactics in the shvanks of russian germans. Issues in Journalism, Education, Linguistics, 39 (3): 487-496 (in Russian). DOI 10.18413/2712-7451-2020-39-3-487-496

\section{Введение}

Шванк является одним из ярких фольклорных жанров литературного репертуара российских немцев, способных отражать особенности национальной картины мира данного этноса. Появившись в России в XVIII веке вместе с первыми переселенцами из Германии, шванк российских немцев в целом сохранил ряд общих черт с исходной формой оригинального немецкого шванка. Однако если в Германии первостепенной функцией шванка была развлекательная, в России в шванке на первый план выступают воспитательный и критикующий аспекты [Москвина, 2017]. Л.И. Москалюк [2016] подчеркивает, что шванк российских немцев - это короткий рассказ юмористического или сатирического содержания, отражающий народный, национальный взгляд на повседневный быт и правила поведения человека в обществе, разоблачая и подвергая критике такие качества, как лень, обжорство, пьянство, скупость, глупость и т.д. [Десятникова, 2009; Жукова, 2019]. Шванк повествуется от лица деревенского жителя или жительницы, которые являются рассказчиками [Москалюк, 2016; Чистюхина, 2019]. В ходе повествования рассказчик не только описывает события, но либо сам вступает в коммуникацию с другими действующими лицами шванка, либо включает в свой рассказ диалоги между другими героями шванков. Часто в подобных коммуникативных ситуациях осуществляется оценка действий отрицательного героя и его перевоспитание.

Обличение пороков персонажа и их исправление достигается в результате применения различных коммуникативных стратегий и тактик, среди которых частотной является манипуляция.

Под коммуникативной стратегией мы, вслед за В.Б. Кашкиным, понимаем «часть коммуникативного поведения или коммуникативного взаимодействия, в которой серия различных вербальных и невербальных средств используется для достижения определенной коммуникативной цели» [Кашкин, 2013, с. 153]. В конкретной ситуации общения коммуникативная стратегия реализуется с помощью речевой стратегии, которую следует определять как принятое говорящим решение о последовательности речевых действий, определяющих речевое поведение в плане выбора оптимальных средств и способов для достижения целей [Иссерс, 2002].

Реализация той или иной коммуникативной стратегии осуществляется с помощью речевых тактик. По мнению Г.А. Копниной, «речевая тактика - это такое речевое действие, которое соответствует определенному этапу в реализации той или иной стратегии и направлено на скрытое внедрение в сознание адресата целей и установок, побуждающих его совершить поступок, выгодный манипулятору» [Копнина, 2008, с.49]. А любое речевое действие, реализующее одно намерение говорящего, может быть представлено одним 
или несколькими речевыми (или тактическими) приемами. При этом под приемом следует понимать «способ построения высказывания или текста, реализующий ту или иную манипулятивную тактику» [Копнина, 2008, с. 49].

Таким образом, коммуникативный процесс с точки зрения речевого воздействия может быть представлен «в виде стройной иерархической системы, в которой тактический ход (или речевой прием) в виде определенных языковых средств служит для реализации речевой стратегии, для достижения целей в речевой ситуации, отражая в то же время общие коммуникативные принципы и установки участников общения» [Кириллова, 2012, с. 27].

Являясь существом социальным, человек всегда «возникает и существует во взаимодействии с другими людьми и под их влиянием» [Кара-Мурза, 2001, с. 11], т.е. в обществе. При этом, существуя в обществе, практически невозможно не столкнуться с теми или иными проявлениями манипулирования, поскольку «общество располагает не только языком (основным средством осуществления манипуляции), но и определенным количеством объектов и субъектов манипуляции», что делает манипуляцию неотъемлемой частью общества [Дидык, 2008, с. 96]. Ю.А. Дидык [2008] отмечает, что очевидной является психологическая составляющая манипуляции. Исследователь предлагает рассматривать манипуляцию как вид психологического воздействия, в результате которого происходит «изменение психологических характеристик личности, групповых норм, общественного мнения или настроения за счет использования психологических, социальнопсихологических закономерностей» [Кабаченко, 1986, с. 13].

В результате такого воздействия осуществляется «скрытое возникновение у другого человека намерений, не совпадающих с существующими желаниями» [Доценко, 1997, с. 59; Двойнина, 2017].

Шванки, герои которых говорят на уникальном диалекте, являются ценным фольклорным наследием российских немцев и активно используются диалектологами для изучения их говоров. Однако с точки зрения коммуникативной прагматики ранее шванки описаны не были.

Цель данного исследования - выявить и описать манипулятивную стратегию, тактики, применяемые героями российско-немецких шванков в процессе речевого взаимодействия, средства языка, при помощи которых реализуется манипуляция в диалогах, а также цели коммуникантов-манипуляторов в конкретных ситуациях общения.

\section{Объекты и методы исследования}

В настоящей работе объектом исследования является коммуникативный процесс, представленный в виде диалогов, в ходе которых осуществляется реализация манипулятивной стратегии и выполняются воспитательная и критикующая функции шванка. В качестве предмета выступает манипулятивная стратегия, речевые тактики и приемы ее реализации.

Фактический материал исследования был отобран методом сплошной выборки. В текстах шванков нами были зафиксированы случаи объективации стратегии манипуляции, а также ряд тактик и приемов, которые далее были изучены при помощи комплекса лингвистических методов - метод лингвистического наблюдения и описания, метод контекстуального анализа.

\section{Результаты и их обсуждение}

В шванках российских немцев манипуляция является одним из способов обличения человеческих пороков и (или) перевоспитания отрицательных героев посредством оказания на них психологического воздействия. Как правило, результатом такого воздействия становится изменение точки зрения или поведения собеседника. Мы рассмотрим особенности реализации коммуникативной стратегии манипуляции на примере нескольких шванков. 
Шванк Фридриха Больгера “Auslauter Lieb” повествует о ленивой жене. В первые дни семейной жизни муж старался угодить ей во всем, не замечая, как она умело манипулирует им:

(1) “Eß nor", saht's Lenje, "ich hun noch net aus geschlofe". Dodrufhotse sich $d r$ Wand zu gedreht un weitr gschlofe. / «Hy, ешь, - сказала Лене, - а я еще не выспалась». После этого она отвернулась к стене и снова заснула.

(2) "Hannes", sahtese, wieermitm Kußgweckthot, "steck's Plittje an un stell Teeuf, ich hunso Koppweh!” / «Ханнес, - сказала она, когда он разбудил ее, поцеловав, - разожги плиту и поставь чайник, у меня так болит голова!»

(3) Aamolhot's dr ganze Togiwrgrechnet, un wie dr Hannes dr Owendhaamkommeis, war er waschnaß. “Hannes”, saht's Lenje, “mir hunkaan Troppe Wasser im Haus. Du bist doch ganz naß, geh un holen Gang Wasser”. / Однажды весь день лил дождь, и Ханес вечером пришел домой мокрым насквозь. «Ханнес, - сказала Лене, - у нас в доме нет ни капли воды. Ты же все равно промок, сходи и принеси воду».

В представленных примерах видно, что доминирующим партнером является женщина. Ее стратегическая цель - переложить все домашние обязанности на мужа. Стратегическая цель мужа на данном этапе общения - угодить любимой жене. Достижение цели женой осуществляется через реализацию манипулятивной стратегии. Для этого женщина использует тактики оправдания отказа (ich hun noch net aus geschlafe; mir hunkaan Troppe Wasser im Haus. Du bist doch ganz naß, geh un holen Gang Wasser) и апелляции к плохому самочувствию (ich hunso Koppweh!). Тактика оправдания отказа в примере (1) иллюстрируется формой императива (Eß nor), отрицательной частицей net, значение которой усиливается наречием поch. Индикаторами тактики апелляции к плохому самочувствию в примере (2) является обращение к мужу (Hannes), форма императива (stecks Plittje an un stell Tee uf), восклицательное предложение и наречие so (ich hun so Koppweh!), способствующее усилению прагматического эффекта. В примере (3) жена оправдывает свой отказ, приводя доводы в пользу того, что именно муж должен сходить за водой, потому что он и так мокрый после дождя. Тактика оправдания отказа реализуется обращением (Hannes), местоимением первого лица единственного числа (mir), имплицитно указывающим на то, что проблема общая. Активный коммуникант использует усилительные наречия doch и ganz и форму императива.

(4) Do is m Hannes dr Geduldfade geplatzt un er hot die zwaa Aamer voll Wasser seim Schatzjeiwrn Kopp gstiilpt. “Lenje”, sahtr, “jetzbiste grodsonaß wieich, gehun holen Gang Wassr, daß de was gekocht kriest”. / И тут терпение Ханнеса лопнуло, и он вылил эти два ведра прямо на голову возлюбленной. «Лене, - сказал он, - теперь ты так же промокла, как и я, иди и принеси воды, чтобы что-нибудь приготовить».

Пример (4) показывает, что позиции собеседников меняются в прямо противоположном направлении. Активную позицию занимает супруг. На данном этапе общения его стратегическая цель состоит в том, чтобы показать свое недовольство поведением жены. Достижению указанной цели способствует стратегия манипуляции, которая воплощается с помощью тактики оправдания отказа. Адресант использует сравнение и усилительные слова (grodsonaß wieich), форму императива и придаточное цели (gehun holen Gang Wassr, daß de was gekocht kriest).

Как видим, стратегия манипуляции в проанализированном шванке, с одной стороны, выступает средством обличения такого человеческого порока, как лень, а, с другой стороны, является методом перевоспитания ленивой жены. После того, как муж выразил свое недовольство и продемонстрировал это и делом, и словом, применив при этом в том числе и стратегию манипуляции, жена изменилась в лучшую сторону.

В шванке Давида Буша “'s Hannesje hat sei Fett kriet” жена главного героя посредством манипуляции отучила его засматриваться на другую женщину. 
(5) Die erste Zeit gungjo alles scheeun gut. Awrufaamolhot die Barwelgmerkt, daß ihr Hannesje immer ofternouchdere Ernaje geguckt hot. Do saataamol die Barwel: “Alter, paß uf, machkaa Bockspring, sunstkriest de dei Fett!"/ Первое время все было замечательно. А потом как-то Барбель заметила, что ее Ханнес все чаще стал заглядываться на Эрну. И тогда Барбель сказала: «Послушай, муженек, ты не дури, иначе тебе влетит».

(6) So sitzt molwiedr's Hannesjeufn Sunntagun kritzelt emsig einen Brief. Die Barwelsaat so ganz ruhig: “Alter, wos schreibst de dann wiedr, wann mr frouge darf?" / Cидит как-то раз Ханнес и старательно пишет письмо. Барбель говорит так спокойно: «Муженек, что ты там опять пишешь, позволь тебя спросить?»

(7) Bei dene Worte hot die Barwel mit dr rechte Hand nouch $m$ Besegegriffe, un mit $d r$ link Hand hot se gewunke: "Kummnormolher, du Schwankeschreiwer! Ich will draachmolunner die Arm greife. Ich will dich haalevundere Krankheit, wu dich souplougt. Mei Arznei is dr Besestiel, dr Pannegriffun die Oufegawel, awr die Arznei helft!" / С этими словами схватила Барбель в правую руку метлу, а левой поманила мужа: «Иди-ка сюда, писака! Я тебе сейчас так помогу. Я тебя сейчас так вылечу от болезни, которая тебя мучает. Мое лекарство - это метла, сковородка и ухват, но оно отлично помогает!»

Из приведенных примеров следует, что главным манипулятором в общении является супруга. Ее стратегическая цель состоит в том, чтобы предотвратить измену мужа. Для достижения своей цели женщина использует коммуникативную стратегию манипуляции, реализуемую с помощью тактик угрозы и притворного заискивания. Тактика угрозы представлена в примере (5): Alter, paß uf, machkaa Bockspring, sunstkriest de die Fett! Очевидными индикаторами данной тактики являются форма императива (paß uf, machkaa Bockspring); наречие sunst, имплицитно содержащее угрозу и указывающее на то, что ожидает мужчину в случае измены; форма второго лица единственного числа Präsens Indikativ, обладающее значением будущности (kriest), фразеологический оборот (kriestdei Fett) и восклицательный знак в конце предложения.

Пример (6) иллюстрирует умелое использование женщиной тактики притворного заискивания (Alter, wos schreibst de dann wiedr, wann $\mathrm{mr}$ frouge darf?), которая реализуется следующими языковыми средствами: вопросительное предложение (wos schreibst de dann wiedr) и вежливая форма обращения (wann mr frouge darf), которая звучит неискренне.

В примере (7) на первый план выступают языковые средства, являющиеся индикаторами тактики угрозы. Для реализации данной тактики активный коммуникант использует форму императива (Kummnormolher) и обращение (du Schwankeschreiwer). Примечательно, что обращение du Schwankeschreiwer звучит уничижительно. Данный эффект достигается за счет использования личного местоимения $d u$ и сложного существительного Schwankeschreiwer. Значение угрозы передают модальный глагол wollen и параллельные конструкции (Ich will draachmolunner die Armgreife. Ich will dichhaalevundere Krankheit, wudichsouplougt), придающие тексту особую эмоциональность. Следует отметить, что слова Krankheit и Arznei в рассматриваемом контексте звучат иронически и обладают переносным значением. Кульминационной является последняя часть высказывания (Меі Arzneiis dr Besestiel, dr Pannegriffun die Oufegawel, war die Arzneihelft!), в котором перечисление средств от болезни мужа, выраженных сложными существительными $d r$ Besestiel, $d r$ Pannegriffun die Oufegawel в наибольшей степени передают угрозу.

Таким образом, в анализируемом шванке стратегия манипуляции является, прежде всего, средством перевоспитания мужа. После угроз со стороны жены супруг перестал мечтать о другой женщине и писать ей любовные письма.

Шванк Эмиля Йоста "Die Wäschmaschin" повествует о мужчине, который был настолько жаден, что заставлял свою жену стирать руками, чтобы не тратить лишних денег на покупку стиральной машины. Соседи, сочувствующие бедной женщине, решили ей помочь и изменить точку зрения скупого супруга. Для достижения данной цели активные 
коммуниканты используют стратегию манипуляции, которая воплощается при помощи тактик понижения статуса отрицательного героя, намека, удивления и упрека.

(8)“Ich hätma Lebtag netg'glaabt, daß unser Nochbr, dr Weinerts Jörg, noch so rickstännig wär. Der loßtsa Marilisbet die Wasch mit dr Hand wasche! Die derf noch netuf 'n Wäschbrett wasche - die hält länger, die Wasch, saat'r..."/ «Я бы никогда в жизни не подумала, что наш сосед, Йорг Вайнерт, такой отстальй. Он заставляет Марилизбет стирать вручную! Ей нельзя пользоваться даже стиральной доской - он говорит, что так стирка дольше...»

Пример (8) иллюстрирует использование говорящим тактики понижения статуса героя, которого необходимо перевоспитать. Реализации указанной тактики способствуют следующие языковые средства: сослагательное наклонение (Ich hät netg'glaabt; wär); гипербола (ma Lebtagnet); прилагательное с отрицательной коннотацией (rickstännig), значение которого усиливается словом so; восклицание, передающее эмоции говорящих (Der loßtsa Marilisbet die Wasch mit dr Hand wasche!); глагол lassen в модальном значении побуждения к действию; модальный глагол dürfen в отрицательной форме для выражения запрета; цитата, передающая слова героя порицания, которые тоже не делают ему чести (die hält länger, die Wasch, saat'r...).

(9) "Do mach ich kee langes Federlesa. Desis doch net so, wie wennr mit 'm Wäschbrett wasche tät, odr mit d'r Hand. Desissoropp-zopp, undo is de Kippel Waschweg!" / «Я долго не канителюсь. Это же не то, что на доске стирать или руками. Раз-два-и куча белья уже выстирана!»

(10) "Das will ich meene", sagte die dickbeinige Milis. "So e Wäschmaschinis mit kee Geld zu bezahle... Awrwißt ihr aach, daßmaheit noch Männer hot, die von ihre Weibsleit mit dr Hand wasche losse?” / “И я о том же, - сказала толстоногая Милис. - Стиральная машина дороже любых денег... А вы знаете, что у нас есть такие мужчины, которые все еще заставляют своих жен стирать вручную?»

В примерах (9) и (10) представлена тактика намека. Говорящий демонстративно нахваливает стиральную машину перед главным героем, намекая таким образом на острую необходимость купить стиральную машине жене. Адресант намеренно использует фразеологизм (mach ich kee langes Federlesa), сравнение (dochnetso, wie wennr mit ' $m$ Wäschbrett) и междометие (ropp-zopp), чтобы наглядно продемонстрировать скорость и легкость, с которой стиральная машина способна справиться с кучей грязного белья.

(11) “Bei uns? In unserem Posjolok?” riefen ein paar Stimmen durcheinander. / «Y нас? В нашем поселке?»- воскликнули сразу несколько голосов наперебой.

(12) “Ja, ja, beiuns. Un noch so 'n Mann, von dem ihr's gar net erwarte tut..." / «Дада, у нас. И это мужчина, от которого вы такого совсем не ожидали ...»

(13) “Na, Milis, wer is denndes?” / «Ну же, Милис, кто он?»

(14) “Mabr auch, jonet gleichalles an die grouß’ Glockbrenge, awrdesisso.” / «Не хочу выносить сор из избы, но это так».

(15) “Na, awr doch!” sagte der Deeres Jaschke. “Des muß awrn richtige Geizhalss in.” / «И все же! - сказал Яшке Деерес. - Он, должно быть, настоящий скупердяй».

Примеры (11) и (13) демонстрируют использование говорящими тактики удивления, которая реализуется вопросительными предложениями (Bei uns? In unserem Posjolok? weris denn des?), обращением (Milis) и междометием (na).

В предложениях (12) и (14) говорящий применяет тактику намека. Рассказчик намеренно отказывается называть человека, который не желает купить своей жене стиральную машину, т.к. этот человек является свидетелем разговора. Цель манипулятора дать понять, что так поступать с супругой нехорошо, и от него, конечно, такого отношения к собственной жене никто не ожидает. В качестве тактического хода можно назвать использование усилительного слова (so), придаточного определительного (von de mihr's garnet erwartetut), фразеологизма (an die grouß’ Glockbrenge). 
Пример (15) демонстрирует использование тактики упрека. Говорящий предполагает, что этот неизвестный мужчина, наверняка, очень жадный. Реализация тактики осуществляется с помощью неодобрительной метафоры (Geizhals), значение которой усиливается прилагательным (richtige).

Итак, в рассмотренном шванке стратегия манипуляции служит средством обличения жадности, невнимательного отношения к жене и методом перевоспитания. После состоявшегося между соседями разговора в присутствии героя, подлежащего перевоспитанию, мужчина, наконец-то, купил жене стиральную машину.

В шванке Андреаса Закса “Der Ausweg” речь идет о шестидесятилетнем мужчине, который после смерти супруги решил снова жениться. Но его дети были категорически против, объясняя это тем, что лишь недавно похоронили мать. Мужчина, в свою очередь, был недоволен отношением детей к нему. Они редко его навещали, а если приезжали, то только за продуктами. А ему хотелось бы иметь рядом человека, готового прийти на помощь и ухаживать за ним. Эту мысль он решил донести до своих детей. Для этого в разговоре с ними он применил стратегию манипулирования.

Am nächsten Morgen blieb Vetter Gustav im Bett. Olga machte Kaffee und deckte den Tisch. / Наследующее утро дядюшка Густав остался в постели. Ольга сделала кофе и накрыла на стол.

(16) “Ich bin net gesund, mei Mahd”, stöhnte Vetter Gustav. / «Мне не здоровится, доченька», - застонал дядюшка Густав.

(17) “Ich hun's im Leib..." / «Живот болит...»

(18)“Ich brauch kaa Arznei meh”, erwiderte Vetter Gustav. “'s is schon zu spät. Ich hun mich vrunreinigt. Du musst mich putze.” / «Мне уже не нужно лекарство, - ответил дядюшка Густав. - Уже слишком поздно. Я обделался. Помой меня».

Примеры (16), (17) и (18) иллюстрируют использование тактики притворства. Мужчина сначала притворился, что болен, а затем - что сходил в туалет под себя. Ввиду своего плохого самочувствия он попросил детей помыть его. Индикаторами тактики притворства является использование параллельных конструкций. Практически все предложения в приведенных примерах начинаются с личного местоимения ich. Адресант употребил отрицательную частицу (net), отрицательное местоимение (kaa), усилительную частицу (zu), способствующие более точному описанию его плохого состояния. Последнее предложение в примере (18) демонстрирует тактику апелляции к чувству долга, что выражается использованием модального глагола (mußt).

(19) “Ich wußt 's, daßdrnet könnt”, meinte Vetter Gustav nach einer Weile beherzt und stieg kerngesund aus dem Bett. “Awermei Fraa wird's könne, unichheirat, ob 'seich gefallt oder net.” / «Я знал, что ты не сможешь, - решительно заявил дядюшка Густав через некоторое время и лихо вскочил с постели. - А моя жена сможет, и я женюсь, нравится вам это или нет».

В примере (19) активным коммуникантом применена тактика объяснения своего поведения. Мужчина пояснил, что на детей у него надежды нет, ухаживать за ним они не готовы, поэтому он собирается жениться. Говорящий намеренно создает эффект противопоставления возможностей детей и будущей жены за счет употребления модального глагола (können) сначала с отрицательной частицей net (netkönnt), а затем в сочетании с глаголом warden (wird'skönne). Эффект противопоставления создается и противительным союзом (awer). Финальную точку в достижении своей коммуникативной цели герой ставит, используя тактику категоричного заявления (unichheirat, ob 'seich gefallt oder net).

Как видим, в проанализированном шванке стратегия манипуляции является средством обличения такого человеческого порока, как неуважение к своим родителям. Однако в данном шванке манипуляция не стала методом перевоспитания детей главного героя. Дети лишь согласились с намерением своего отца жениться, потому что не захотели взять 
на себя заботу о нем. Тем не менее, главному герою удалось успешно применить манипулятивную стратегию и достичь поставленной коммуникативной цели.

Проведенное исследование показало, что коммуникативная стратегия манипуляции широко применяется в шванках российских немцах. Ее воплощению способствуют многочисленные речевые тактики. Для реализации речевых тактик коммуниканты используют различные тактические приемы, представленные многообразием языковых средств: лексических, грамматических и стилистических (см. таблицу).

Реализация коммуникативной стратегии манипуляции в шванках российских немцев

Implementation of the communicative strategy of manipulation in the shvanks of Russian Germans

\begin{tabular}{|c|c|c|}
\hline Порок & Тактика & Языковые средства \\
\hline \multirow{2}{*}{ лень } & оправдания отказа & $\begin{array}{l}\text { императив, отрицательные частицы, слова- } \\
\text { усилители, обращение, личные местоимения, } \\
\text { сравнение, придаточное цели }\end{array}$ \\
\hline & $\begin{array}{l}\text { апелляции } \\
\text { к плохому } \\
\text { самочувствию }\end{array}$ & $\begin{array}{l}\text { обращение, императив, восклицательные пред- } \\
\text { ложения, слова-усилители }\end{array}$ \\
\hline \multirow[t]{2}{*}{ измена } & угрозы & $\begin{array}{l}\text { императив, наречия, временная форма Präsens } \\
\text { Indikativ, фразеологические обороты, восклица- } \\
\text { тельные предложения, обращение + личное ме- } \\
\text { стоимение, сложные существительные, модаль- } \\
\text { ные глаголы, параллельные конструкции, слова } \\
\text { с отрицательной коннотацией, слова в перенос- } \\
\text { ном значении }\end{array}$ \\
\hline & притворного заискивания & $\begin{array}{l}\text { вопросительные предложения, вводные кон- } \\
\text { струкции }\end{array}$ \\
\hline \multirow{4}{*}{$\begin{array}{l}\text { жадность / } \\
\text { невнимательное } \\
\text { отношение } \\
\text { к жене }\end{array}$} & $\begin{array}{l}\text { понижения статуса отрица- } \\
\text { тельного героя }\end{array}$ & $\begin{array}{l}\text { сослагательное наклонение, гипербола, слова с } \\
\text { отрицательной коннотацией, слова-усилители, } \\
\text { восклицательные предложения, модальные гла- } \\
\text { голы, цитаты }\end{array}$ \\
\hline & намека & $\begin{array}{l}\text { фразеологические обороты, сравнения, междо- } \\
\text { метия, слова-усилители, придаточное опреде- } \\
\text { лительное }\end{array}$ \\
\hline & удивления & $\begin{array}{l}\text { вопросительные предложения, обращение, } \\
\text { междометия }\end{array}$ \\
\hline & упрека & метафора, слова-усилители \\
\hline \multirow{4}{*}{$\begin{array}{l}\text { неуважение } \\
\text { к родителям }\end{array}$} & притворства & $\begin{array}{l}\text { личные местоимения, параллельные конструк- } \\
\text { ции, отрицательные частицы и местоимения, } \\
\text { слова-усилители }\end{array}$ \\
\hline & $\begin{array}{l}\text { апелляции } \\
\text { к чувству долга }\end{array}$ & модальные глаголы \\
\hline & $\begin{array}{l}\text { объяснения своего } \\
\text { поведения }\end{array}$ & $\begin{array}{l}\text { модальные глаголы, отрицательные частицы, } \\
\text { союзы и союзные слова }\end{array}$ \\
\hline & $\begin{array}{l}\text { категоричного } \\
\text { заявления }\end{array}$ & $\begin{array}{l}\text { союзы, временная форма Präsens Indikativ, при- } \\
\text { даточное условия }\end{array}$ \\
\hline
\end{tabular}

\section{Заключение}

В ходе исследования было установлено, что среди коммуникативных стратегий, представленных в шванках для реализации их основных функций, наиболее актуальной 
становится коммуникативная стратегия манипуляции. Манипулятивные стратегии и тактики в шванках российских немцев способствуют выполнению таких его функций, как воспитательная и критикующая и позволяют вскрыть некоторые особенности национального характера в языковой картине мира российских немцев. Критике подвергаются социально-нравственные недостатки общества: лень, жадность, неуважение к родителям, измена и т.д. Известно, что шванкам свойственна некоторая степень ироничности и комичности. Именно эти свойства шванка, будучи в том числе и частью манипуляции, позволяют отобразить и осмыслить реалии жизни, кажущиеся в данном обществе неправильными и иногда жестокими, благодаря чему можно составить представление о ценностной картине мира российских немцев.

Исходя из проанализированных шванков, можно сделать вывод о высокой результативности манипулятивных стратегий и тактик. Практически каждая рассмотренная нами коммуникативная ситуация закончилась стратегической победой манипулятора, достигшего поставленной им коммуникативной цели. Следует также отметить, что в шванках представлены и ситуации, в которых манипулируемому удавалась переломить ситуацию, в результате чего он сам становится активным коммуникантом, что всегда сопровождается сменой цели коммуникации.

Полученные результаты вносят вклад в изучение островных говоров российских немцев и могут быть полезны для лингвистов, работающих в области российской немецкой диалектологии.

\section{Список источников}

1. Кара-Мурза С.Г. 2001. Манипуляция сознанием в России сегодня. Под ред. С. КараМурза. М., Алгоритм, 544 с.

2. Кашкин В.Б. 2013. Введение в теорию коммуникации. Под ред. В.Б. Кашкина. М., Флинта, Наука, 224 с.

3. Копнина Г.А. 2008. Речевое манипулирование. Под ред. Г.А. Копниной. М., Флинта, 176 c.

\section{Список литературы}

1. Двойнина Е.В. 2017. Стратегии и тактики речевой манипуляции в инаугурационной речи Д. Трампа. Филологические науки. Вопросы теории и практики, 12 (4): 76-78.

2. Десятникова И.В. 2009. Особенности структурно-композиционной организации шванка российских немцев. Мир науки, культуры, образования, 6: 43-45.

3. Дидык Ю.А. 2008. Методологические основы изучения речевой манипуляции в оригинале и переводе (на материале пьес Б. Шоу). Известия Российского государственного педагогического университета им. А.И. Герцена, 80: 95-101.

4. Доценко Е.Л. 1997. Психология манипуляции: феномены, механизмы и защита. Под ред. Е.Л. Доценко. М., ЧеРо; Изд-во МГУ, 344 с.

5. Жукова Л.В. 2019. Репрезентация концепта труд в языке российских немцев (на материале шванков). Филологические науки. Вопросы теории и практики, 12, 4: 40-45.

6. Иссерс О.С. 2016. Речевое воздействие. Под ред. О.С. Иссерс. М., Флинта, 224 с.

7. Кабаченко Т.С. 1986. Активизация человеческого фактора: методы психологического воздействия. Психологический журнал, 4 (7): 11-12.

8. Кириллова Н.Н. 2012. Коммуникативные стратегии и тактики с позиции нравственных категорий. Вестник НГТУ им. Р.Е. Алексеева. Серия «Управление в социальных системах. Коммуникативные технологии», 1: 26-33.

9. Москалюк Л.И. 2016. Отражение особенностей разговорной речи в шванках российских немцев. Вестник Томского государственного университета. Филология, 2 (40): 45-56.

10. Москвина Т.Н. 2017. Средства выражения темпоральности в текстах шванков российских немцев. Культура и текст, 3 (30): 167-179.

11. Чистюхина Е.А. 2019. Шванк российских немцев как отражение этнической картины мира. Мир науки, культуры, образования, 6-2: 47-48. 


\section{References}

1. Dvoynina E.V. 2017. Strategii i taktiki rechevoy manipulyatsii $v$ inauguratsionnoy rechi D. Trampa [Strategies and tactics of speech manipulation in D. trump's inaugural speech]. Philology. Theory \& Practice, 12 (4): 76-78.

2. Desyatnikova I.V. 2009. Osobennosti strukturno-kompozitsionnoy organizatsii shvanka rossiyskikh nemtsev [Features of the structural and compositional organization of the schwank of Russian Germans]. The world of science, culture and education, 6: 43-45.

3. Didyk Yu.A. 2008. Metodologicheskie osnovy izuchenie rechevoy manipulyatsii v originale i perevode (na materiale p'es B. Shou) [Methodological bases the study of speech manipulation in the original and translation (based on the material of B. Shaw's plays)]. Izvestia: Herzen University Journal of Humanities \& Sciences, 80: 95-101.

4. Dotsenko E.L. 1997. Psikhologiya manipulyatsii: fenomeny, mekhanizmy i zashchita [Psychology of manipulation: phenomena, mechanisms, and protection]. Ed. E.L. Dotsenko. M., Publ. CheRo; Izd-vo MGU, 344 p.

5. Zhukova L.V. 2019. Reprezentatsiya kontsepta trud v yazyke rossiyskikh nemtsev (na materiale shvankov) [Representation of the concept of labor in the language of Russian Germans (based on the material of schwankov)]. Philology. Theory \& Practice, 12 (4): 40-45.

6. Issers O.S. 2016. Rechevoe vozdeystvie [Speech influence]. Ed. O.S. Issers. M., Publ. Flinta, $224 \mathrm{p}$.

7. Kabachenko T.S. 1986. Aktivizatsiya chelovecheskogo faktora: metody psikhologicheskogo vozdeystviya [Activation of the human factor: methods of psychological influence]. Psikhologicheskiy zhurnal (7), 4: 11-12.

8. Kirillova N.N. 2012. Kommunikativnye strategii i taktiki s pozitsii nravstvennykh kategoriy [Communication strategies and tactics from the position of moral categories]. Vestnik NGTU im. R.E. Alekseeva. Seriya «Upravlenie v sotsial'nykh sistemakh. Kommunikativnye tekhnologii», 1: 26-33.

9. Moskalyuk L.I. 2016. Otrazhenie osobennostey razgovornoy rechi v shvankakh rossiyskikh nemtsev [The reflection of the peculiarities of colloquial speech in svannah Russian Germans]. Tomsk State University Journal of Philolog, 2 (40): 45-56.

10. Moskvina T.N. 2017. Sredstva vyrazheniya temporal'nosti v tekstakh shvankov rossiyskikh nemtsev [Means of expression of temporality in the texts of Shunkov Russian Germans]. Kul'tura i tekst, 3 (30): 167-179.

11. Chistyukhina E.A. 2019. Shvank rossiyskikh nemtsev kak otrazhenie etnicheskoy kartiny mira [Schwank of Russian Germans as a reflection of the ethnic picture of the world]. The world of science, culture and education, 6-2: 47-48.

\section{ИНФОРМАЦИЯ ОБ АВТОРАХ}

Чистюхина Евгения Александровна, кандидат филологических наук, доцент, профессор кафедры перевода и переводоведения Новосибирского военного институт имени генерала армии И.К. Яковлева войск национальной гвардии Российской Федерации, г. Новосибирск, Россия

Жукова Любовь Владимировна, старший преподаватель кафедры перевода и переводоведения Новосибирского военного институт имени генерала армии И.К. Яковлева войск национальной гвардии Российской Федерации, г. Новосибирск, Россия

\section{INFORMATION ABOUT THE AUTHORS}

Evgeniya A. Chistyukhina, Candidate of Philological Sciences, associate Professor, Professor, Department of translation and translation studies, Novosibirsk military Institute named after General of the army I. K. Yakovleva of the national guard of the Russian Federation, Novosibirsk, Russia

Lyubov V. Zhukova, Senior Lecturer, Department of translation and translation studies, Novosibirsk military Institute named after General of the army I. K. Yakovleva of the national guard of the Russian Federation, Novosibirsk, Russia 